Никита Быстров

ORCID: 0000-0002-2929-5821

Уральский федеральный университет имени первого Президента России Б.Н. Ельцина

Екатеринбург, Россия

\title{
ИСПОВЕДАЛЬНОСТЬ В ПОЭЗИИ ВЯЧЕСЛАВА ИВАНОВА: ПРЕДВАРИТЕЛЬНЫЕ ЗАМЕЧАНИЯ
}

https://doi.org/10.34739/clit.2020.14.12

\section{CONFESSIONALITY IN THE POETRY OF VYACHESLAV IVANOV: PRELIMINARY REMARKS}

\begin{abstract}
The article traces parallels between some confessional situations in the poetry of Vyacheslav Ivanov and the Confessions of St. Augustine. The question is raised about the ability of Ivanov`s symbolism to reproduce the existential uncertainty (ignorance of the further path, the actual rejection of its foreshadowing by culture and intellectual experience), to which the confession should lead the subject, if s/he follows the principle of Augustine `s "transcende te ipsum”. When the state of confession is pre-established by a system of symbols with a „ready” meaning, it risks losing its uniqueness: the confession can be replaced by some universal "scheme" of confessionality, which happens in a number of the Ivanov`s poems. Thus, the article delineates one of the possible perspectives of the further study of the claimed topic.

Keywords: confession, confessional situation, „transcendence”, „turn of will”, repentance, symbolic form.
\end{abstract}

Если иметь в виду под исповедью сообщение о событиях внутренней и внешней жизни автора или его героя, сопряженное, как отмечает Н. Казанский, с претендующей на искренность «оценкой собственных действий и поступков» ${ }^{1}$, притом что «оценка эта дается перед лицом Вечности», и если учесть, кроме того, что исповедь предполагает такое самораскрытие исповедующегося, при котором его «я» оказывается ничем незаместимым, обнаженным, лишенным

\footnotetext{
${ }^{1}$ Н. Казанский, Исповедь как литературный жанр, „Вестник истории, литературы и искусства" 2009, т. 6, с. 85.
} 
покровов и масок, то, кажется, поэзия Вяч. Иванова- не самый подходящий объект для разговора об «исповедальности». Это поэзия метафизически углубленная, со сложными религиозно-философскими темами, с символикой, репрезентирующей порой весьма отвлеченные сущности, с преобладанием либо одического, либо медитативного, либо прямо «учительного» (то есть скорее проповеднического, чем исповедального) тона. И все-таки у Вяч. Иванова есть стихи, в которых можно вполне отчетливо расслышать ноты исповеди, хотя эта исповедь облечена в достаточно своеобразную форму. Именно об этом своеобразии и пойдет речь в настоящей статье.

Если задаться вопросом о том, какой из классических текстов служит для Вяч. Иванова ключевым прообразом (или моделирующим основанием) исповедальности, то ответ может быть вполне однозначным: Исповедь Блаженного Августина. В самых разных текстах поэта встречаются цитаты из этой книги, как явные, так и скрытые (например, по наблюдению Джудит Кальб, в подтексте Римских сонетов можно распознать отзвук мотива религиозного обращения, связанного с переездом Августина в Медиолан - город, аналогом которого в этом смысле выступает поздний ивановский

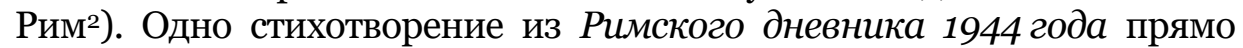
проецирует сжатое до краткой схемы событийно-биографическое содержание Исповеди на прошлое лирического alter ego Вяч. Иванова (в эпиграф здесь вынесены две цитаты: «Нельзя тому быть, чтобы стольких слез твоих чадо погибло» и «И вот, в саду, слышу из соседнего дома голос, как будто отроческий (отроковицы ли - не знаю), часто повторяющий на распев слова: „Возьми и читай, возьми и читай”»):

И я был чадо многих слез;

И я под матерним покровом

И взором демонским возрос,

Не выдан ею вражьим ковам.

А после ткач узорных слов

Я стал, и плоти раб греховной,

И в ересь темную волхвов

Был ввержен гордостью духовной.

\footnotetext{
2 Cm.: J. Kalb, Lodestars on the Via Appia: Vjaceslav Ivanov `s „Roman Sonnets” in Context, „Die Welt der Slaven” 2003, vol. XLVIII, p. 33-34. В связи со сказанным может быть интересен тот факт, что отъезд Вяч. Иванова с детьми из России в Италию состоялся 28 августа 1924 года - в день Блаженного Августина. Описывая события этого дня, Лидия Иванова, дочь поэта, замечает между прочим, что Августина «Вячеслав очень почитал» (Л. Иванова, Воспоминания. Книга об отце, подгот. текста и коммент. Дж. Мальмстада, Москва 1992, с. 124).
} 
И я ответствовал: «Иду»,

От сна воспрянув на ночлеге;

И, мнится, слышал я в саду

Свирельный голос: «tolle, lege» (III, 628)3.

Нетрудно заметить, что в этом стихотворении воспроизводится не одно событие, а как бы общая канва августиновой жизни до обращения: подобно герою Исповеди, лирический герой Вяч. Иванова был защищен «покровом» матери, «ткал узорные слова» (поэзия и вообще «изящная словесность» в данном случае выступают как параллель к занятиям Августина риторикой), был «рабом плоти» и приверженцем «темной ереси» (в случае Августина это манихейство, а в случае Вяч. Иванова, видимо, то, что в его творчестве может входить в противоречие с христианской традицией), и, наконец, некогда услышал тот зов, который у Августина звучит как «tolle, lege», «возыми, читай». Ясно, что Исповедь здесь представляется в качестве «прообразующего» текста жизненного пути.

Думается, однако, что задним числом Вяч. Иванов мог бы отвести подобную роль каким-то иным текстам - из ряда столь же значительных. Для него важно не столько то, что относится к содержанию книги Августина, сколько то, что связано с используемым в ней методом исповедального самовыражения. Точнее сказать, для него важен принцип, лежащий в основе этого метода.

Как известно, исповедь Августина - это такая интроспекция, которая нисходит от внешнего человека к внутреннему, или от того, что субъект «знает» о себе - к тому, чего он «не знает» 4 . «Биографическое» в этом движении как бы меркнет, «психологическое» (связанное с событиями, впечатлениями и вообще всем опытом индивидуальной души) преодолевается. Уходит на дальний план и само узко понятое «я»: «Я обратился к себе и сказал: „Ты кто?” И ответил: „Человек” $(\mathrm{X}, 6)^{5}$. Этот «Человек» (образ Божий) не может быть «моим» или чьим-либо. Скорее это - исходное начало «человеческого» вообще, в аспекте которого «я» субъекта исповеди и все остальные «я»- едины. Здесь, по удачному выражению

\footnotetext{
3 Здесь и далее сочинения Вяч. Иванова цитируются по изданию: В. Иванов, Собрание сочинений в 4 томах, Брюссель 1971-1987 - с указанием тома римской и номера страницы арабской цифрой в скобках.

4 Ср.: «Итак, я исповедуюсь и в том, что о себе знаю, исповедуюсь и в том, чего о себе не знаю, ибо то, что я о себе знаю, я знаю, озаренный Твоим светом, а то, чего о себе не знаю, я не буду знать до тех пор, пока мрак мой не станет как полдень $($ Ис. 58,19$)$ пред лицом Твоим» $(\mathrm{X}, 5)$ (Блаженный Августин Аврелий, Исповедь, пер. М. Сергиенко, Москва 2005, с. 319).

5 Ibidem, c. 321.
} 
Л.М. Баткина, развернута «иная, неведомая мера индивидного» 6 - то, чем этот субъект обладает, но, по существу, не владеет. По отношению к нему личное «я» («свое», частное, отдельное), как говорит Августин, «прах и пепел»; он же, этот «Человек» в человеке, остается незыблемым, или, что то же, истинно сущим, поскольку основание его - не в «я», а в Боге, и Бог, посредством веры, познается как недосягаемый предел его глубины. Вспомним, как в начале второй книги Монологов Августин говорит: «Боже, пребывающий неизменным, позволь мне узнать себя, позволь узнать Тебя!»7, полагая, что эти две линии познания имеют, по существу, один и тот же предмет. И о том же - в Исповеди: «Меня не было бы, Боже мой, вообще меня не было бы, если бы Ты не был во мне. Нет, вернее: меня не было бы, не будь я в Тебе» $(\mathrm{I}, 2)^{8}$.

Общий принцип, на который ориентирована исповедальная речь Августина, восходит к императиву «transcende te ipsum», «превзойди себя» (или, в переводе Вяч. Иванова, «прейди себя»), сформулированному в трактате Об истинной религии (гл. 39): «Старайся познать, что такое высшее согласие, вне себя не выходи, а сосредоточься в самом себе, ибо истина живет во внутреннем человеке; найдешь свою природу изменчивой - стань выше самого себя [курсив наш. - H. Б.]»9. Поскольку о значении этого принципа для Вяч. Иванова (он именует его принципом «трансцензуса») написано уже довольно много, мы не будем специально на этом останавливаться (отметим только, что разработка темы «Иванов и Августин» во многом - заслуга польских исследователей ${ }^{10}$ ). Из многочисленных высказываний поэта, по-разному варьирующих мотив «трансцензуса», приведем лишь несколько, имея в виду, прежде всего, их близость к августиновой концепции «самопревосхождения» субъекта, постигающего себя самого.

Так, в статье Символика эстетических начал Вяч. Иванов пишет: «Дух подымается из граней личного, чтобы низойти в сферу

6 Л. Баткин, «Не мечтайте о себе»: о культурно-историческом смысле «Я» в «Исповеди» бл. Августина, [в:] Л. Баткин, Европейский человек наедине с собой. Очерки о культурно-исторических основаниях и пределах личного самосознания, Москва 2000, с. 70.

7 А. Блаженный, Творения в 4 томах, т. I, Об истинной религии, Санкт-Петербург Киев 2000, с. 339.

8 А.А. Блаженный, Исповедь, с. 5 .

9 А. Блаженный, Творения в 4 томах, т. I, Об истинной религии, с. 441-442.

${ }_{10}$ См., например: А. Дудек, Идеи блаженного Августина в поэтическом восприятии Вяч. Иванова, „Europa Orientalis. Studi e Ricerche sui Paesi e la Culture dell'Est Europeo” 2002, № 1 (XXI), p. 353-367; М. Цимборска-Лебода, О понятии «трансцензуса» у Вячеслава Иванова: к проблеме «Вяч. Иванов и Блаженный Августин», [в:] Sub Rosa: Köszöntő köniv Léna Szilárd tiszteletére, Budapest 2005, s. 123-133. 
того личного, которое лежит уже вне тесного я» (I, 827). В другой работе, Копъе Афины, он утверждает: «Кто волит своего $Я$, тот знает, что не обрел его» (I, 732), и «кто проникся (...) пафосом самоискания, тот (...) погружается в целое и всеобщее» (I, 732). В статье Ты еси дается еще одно положение, важное для уяснения сути «трансцензуса»: «Небо в человеке; оно разоблачается в его сознании чрез внутренний поворот воли ( $\mu \varepsilon \tau a ́ v o ı)$. Торжествующее в человеке внутреннее Небо есть „царство небес”. В глубине нашего Неба есть Отец» (III, 267). Параллель к этому тезису - сонет Внутреннее небо из книги стихов Свет вечерний, где это «небо» уподоблено «шатру», «почив» в котором, спящий мог бы увидеть «Сидящего средь Града на престоле» и осознать свое тождество с Ним:

Когда бы ты почил в голубизне

Того шатра, увидел бы во сне

Сидящего средь Града на престоле.

Слепительный не ослепил бы день

Твоих очей, и не смутила боле

Мысль: «Он - я сам!» Ты был бы - ночь и сень (III, 563).

Наконец, упомянем случай прямого цитирования приведенного выше высказывания из Монологов Августина в стихотворении Eritis Sicut Dei (Кормчие звезды):

Хор, прорицая, пел: «Се Человекобог!

Кто зрел его, в себе творит ему чертог!

Кто вышел в путь, дойдет до светлого порога;

Кто познает себя, в себе познает БОГА!..» (I, 574).

Говоря в статье Ты еси о «повороте воли», который необходим для «разоблачения в сознании» «внутреннего неба», Вяч. Иванов обозначает его греческим термином $\mu \varepsilon \tau \dot{v} v o l \alpha$, принятым христианской традицией в значении «покаяние» (ср. о «метанойе» как «преображении всего душевного склада» в статье Ницие и Дионис (I, 721), а также употребление евангельского «метанойете», «покайтесь», в шестом стихотворении первой части мелопеи Человек: «Когда Пришлец METANOEITE, / Взглянув, как небо, возгласил» (III, 201)). Через сопряжение с этим понятием не только «поворот воли», но и сам «трансцензус» приобретает покаянный оттенок: это не просто открытие иного «я» («другого») в «я» «тесном», узко индивидуальном, но такое его открытие, которое связано покаянием и раскаянием, составляющим непременный элемент исповедального действия. Отсюда можно заключить, что либо латентно, либо открыто 
августиново «прейди себя» (как философско-теологический принцип и как путь «я», изображаемый поэтически) у Вяч. Иванова несет в себе некий исповедальный элемент.

Постулат «прейди себя» является непременным внутренним ориентиром всех персонажей ивановской поэзии, всех «я», которые в ней фигурируют, в том числе и «я», наиболее близкого к автору (условно «автобиографического»). В этом смысле понятна неприязнь Вяч. Иванова к тому, что он называет «субъективной поэзией». По его мнению, субъективное в поэзии, равно как и в искусстве в целом, должно быть преодолено и замещено иным началом - уже не столько психологическим, сколько онтологическим. Как сказано в поздней статье Мысли о поэзии, «без „очищения” (катарсиса), достигнутого (...) внутренним отрешением от себя самого, не светится над произведением та потусторонняя улыбка хотя бы только предчувственной сверхличной гармонии, которая служит для людей знамением подлинности мусического сообщения» (III, 655).

Как видим, в том, что касается концептуальных предпосылок исповедальной речи (или просто речи «о себе»), Вяч. Иванов следует за Августином. Однако во внутреннем строе этой речи между ним и автором Исповеди есть, по крайней мере, одно существенное отличие. В Исповеди Августина «совлечение» героем с себя своего «тесного» биографического «я» приводит его к состоянию крайней неопределенности, выход из которого сам герой указать не может. Спрашивая себя: «Ты кто?» и отвечая: «Человек», он чувствует, что в нем уже не осталось ничего «своего» («свое» - не истина), что он не знает себя, а, следовательно, не знает и пути, по которому он должен двигаться к себе истинному. Здесь - поворот от знания к упованию, к вере. «Цель и смысл „самоотчета-исповеди”, - пишет Л. М. Баткин, - в его самопрекращении, самоотдаче, в даровании всякому „я” (и „самоотчету”) высшей бессмыслицы... Ибо Божественный „смысл” таковым не является: он есть предмет не понимания, а веры. Он неизреченный ${ }^{11}$. В самом деле, исповедь с таким Адресатом, как у Августина, должна включать в себя момент если не «бессмыслицы», то «неосмысленности», невозможности самостоятельно осмыслить себя, когда задача приведения себя к себе как бы передоверяется Богу (в противном случае и сама исповедь была бы не нужна). Здесь то, что Августин в восьмой книге называет «оковами моей собственной воли», разрушено, и «я» - безвольно (заметим, что и для Вяч. Иванова тема «безволья» важна; ср., например: «Сладко мне мое безволье / Доверять валам надежным...» (II, 268)); в нем, через него действует воля высшая.

${ }^{11}$ Л. Баткин, op. cit., с. 88. 
Возьмем теперь стихотворение Вяч. Иванова Палинодия (1927), которое некоторые исследователи прямо называют «исповедальным» ${ }^{12}$ :

И твой гиметский мед ужель меня пресытил?

Из рощи миртовой кто твой кумир похитил?

Иль в вещем ужасе я сам его разбил?

Ужели я тебя, Эллада, разлюбил?

Но, духом обнищав, твоей не знал я ласки,

И жутки стали мне души недвижной маски,

И тел надменных свет, и дум Эвклидов строй.

Когда ж, подземных флейт разымчивой игрой

В урочный час ожив, личины полой очи

Мятежною тоской неукротимой Ночи,

Как встарь, исполнились - я слышал с неба зов:

«Покинь, служитель, храм украшенный бесов».

И я бежал, и ем в предгорьях Фиваиды

Молчанья дикий мед и жесткие акриды (III, 553).

Палинодия, как известно, есть «отречение», отказ от прошлого. Речь идет, говоря обобщенно, о том, что ивановский герой находится на распутье между «Элладой» как источником и контекстом прежнего, кажется, уже отвергнутого мировоззрения, и чем-то новым - новой парадигмой мысли и судьбы. Это переход к иному бытийному состоянию: в прошлом - царство телесности и «эвклидовой» логики, в настоящем - «обнищание души», которую все это уже не радует, а ужасает, будущее же как будто (подчеркнем: как будто) неизвестно. Нет сомнения в том, что герой Вяч. Иванова, как и сам поэт (здесь случай особенно тесного сближения между ними), переживает чувство потерянности, неизвестности, неопределенности. Но как это показано? Ключевой образ стихотворения - «Фиваида»: «И я бежал, и ем в предгорьях Фиваиды / Молчанья дикий мед и жесткие акриды». «Фиваида» - символ покаяния: по словам Памелы Дэвидсон, в поэзии Вяч. Иванова (не только здесь, но и, например, в поэме Младенчество, где с «родимой Фиваидой» также связан мотив «бегства», см.: I, 249) это - «образ идеальной чистоты духа, к которой поэт должен стремиться всю жизнь» ${ }^{13}$. Если иметь в виду замечание Роберта

\footnotetext{
12 См., например: Д. Мицкевич, Реалиоризм Вячеслава Иванова, [в:] Христианство и русская литература: взаимодействие этнокультурнъх и религиозно-этических традиций в русской мысли и литературе, Санкт-Петербург 2010, с. 295; А. Шишкин, Вячеслав Иванович Иванов (1866-1949), [в:] Литература русского зарубежья (1920-1940): учебник для высших учебных заведений Российской Федерации, отв. ред. Б. Аверин, С. Титаренко, Санкт-Петербург 2011, с. 421.

13 P. Davidson, Hellenism, Culture and Christianity: The Case of Vyacheslav Ivanov and His „Palinode" of 1927, [in:] Russian Literature and The Classics, edited by Peter I. Barta, Amsterdam 1996, p. 83-116.
} 
Льюиса Джексона о том, что Вяч. Иванов не дает определенного ответа на вопрос «Ужели я тебя, Эллада, разлюбил?», и поэтому трудно сказать, покидает ли он окончательно «классический мир»14, то вполне возможно, что его «Фиваида» оказывается символом как бы двоящимся: соотнесенным одновременно и с христианским в точном смысле, и, условно говоря, с «аполлоническим» (чисто эстетическим) покаянием (в этом случае отречение от «Эллады» можно было бы понимать как отказ по преимуществу от «дионисийских» настроений).

Как бы то ни было, герой Палинодии - в своей внутренней «Фиваиде», «на покаянии». Этот образ отчетливо предопределяет картину его будущего - либо по одной (христианской), либо сразу по двум (христианской и «аполлонической») линиям. Предопределяет, или конституирует то будущее, которое на покаянном распутье, как уже говорилось, обычно бывает неопределенным. Августин в типологически сходном состоянии не знает, где он, а Вяч. Иванов знает. Августин чувствует, что в этой ситуации символы, в окружении которых живет человек (кроме евангельских, может быть), временно недействительны (ибо, в самом деле, для чего тогда уповать на Бога?), а для Вяч. Иванова они действительны всегда и, более того, они всегда предвосхищают и как бы загодя «расчерчивают» топос покаянного (исповедального, любого вообще) действия. Августин - в «междумирном»- смутном и неопределенном - пространстве, а Вяч. Иванов - в пространстве культурном или, точнее, текстуальном, иначе говоря, в мире «готовых» (хотя и непрестанно обновляемых) символических форм.

Из ряда таких же форм - образы Рахили и Лии из стихотворения с августиновским названием Transcende te ipsum (сборник Прозрачность). Они словно бы предвосхищают разрешение ситуации душевного «распутья», коррелирующего (хотя и на большой дистанции) с «распутьем» исповедальным. Два пути под светом «вечной Софии»: символом одного выступает Рахиль, а другого - Лия.

...Одна зовет: «Прейди

Себя, - себя объемля в беспредельном».

Рахиль: «Себя прейди в себя сойди».

И любит отчужденного в Одном,

А Лия - отчужденного в Раздельном.

И обе склонены над темным дном (I, 783).

${ }^{14}$ R.L. Jackson, Vjaceslav I. Ivanov and the Question of Art. The Roman Notebook: February 18, 1944 „Nudus Salta! Cel `Iskusstva...”, „Russian Literature” 1998, № XLIV, p. 300. 
Рахиль и Лия - ветхозаветные образы, воспринятые Вяч. Ивановым от Данте (созерцательная и деятельная любовь), а Данте, как сказано в авторском примечании к этим стихам, интерпретирует их «по Фоме Аквинскому» (I, 861). Фома же, добавим от себя, заимствует эту интерпретацию из сочинений предшественников, возможно, из книги Августина Против Фауста Манихея. «Ангел порыва», упомянутый двумя строфами ранее, по-видимому, может быть понят как персонификация платоновского Эроса. София, о которой говорится здесь же («Вечная София - / Обеим свет»), тоже обладает вполне определенным религиозно-философским значением. Словом, формы-модели «самопревосхождения» здесь уже заданы, траектории его как бы раз и навсегда прочерчены. Может быть, только символ «темного дна», над которым «склонены» Рахиль и Лия, прямо не отсылает к текстам прошлого, хотя и он, бесспорно, предполагает их.

Та же ситуация - в текстах не с «отвлеченным» (как в Transcende te ipsum), а с гораздо более близким к автору лирическим героем - размышляющим, вспоминающим, кающимся. Отчасти мы уже видели это на примере Палинодии. Упомянем еще один текст пусть не исповедальный в строгом смысле и даже не вписывающийся в парадигму «трансцензуса», но тесно связанный с проблемой покаяния. Это стихотворение 1919 года Г. И. Чулкову (Да, сей костер мы поджсалали... (IV, 81)). Его тема - вина интеллигенции модернистского круга, с ее мечтами о «преображении мира», во всем том, чем разрешилась на деле русская революция. Вяч. Иванов признает эту вину («совесть правду говорит»), предчувствуя, что в революционном пожаре «сгорит наше сердце», но здесь - не просто сердце, а «сердце-Феникс», которое отсылает к множеству подобных образов у самого Вяч. Иванова, и также, по замечанию C. С. Аверинцева, к важному для поэта призыву Гете «Stirb und werde!», «умри и стань» ${ }^{15}$. Дальше появляется образ Эолова меха: развязавшие этот мех не должны «корить» поднявшиеся из-за них бури. В строках «Поет Трагедия: „Все грех, / Что действие”, варьируется одна из излюбленных тем Вяч. Иванова (тема «Прометея», «Тантала», стихотворения-трактата Слоки), а также цитируется (здесь мы снова следуем за Аверинцевым) эсхиловский Агамемнон ${ }^{16}$. Наконец, в том, что здесь говорит «Трагедия» - «Все за всех» - узнаются знаменитые слова старца Зосимы из Братьев Карамазовьх.

Этому стихотворению Вяч. Иванова, как и большинству других его текстов, цитатность, без сомнения, органична. Это цитатность средневекового экзегета или ренессансного гуманиста, без нее

15 С. Аверинцев, Стратегия цүитаты в поэзии Вячеслава Иванова, „Europa Orientalis” 2002, № 1, c. 23.

${ }^{16}$ Ibidem, c. 24. 
ивановская поэзия просто не существует. Другое дело, что когда Вяч. Иванов говорит «о себе» (при неизбежной в поэзии условности этого «о себе»), символика, отсылающая к множеству источников, как бы скрадывает уникальность и единственность описываемых экзистенциальных состояний. В самом деле, чъи переживания передаются образами «зова с неба», «Фиваиды», «сердца-Феникса», эдипова или прометеева трагического греха и т. п.? Прежде всего, это конечно, переживания ивановского героя, но в то же время - и всех тех, чей опыт аккумулирован памятью этих и подобных символов (вспомним, что любой символ, по Вяч. Иванову, «многоименен»), и, главное, тех, для кого они еще станут средством самовыражения.

Обобщая, можно сказать, что в тех относительно немногочисленных стихотворениях Вяч. Иванова, где звучат мотивы исповеди и покаяния, на первый план выходит не столько исповедующаяся и кающаяся душа, которая не знает своего пути, сколько символически означенная ситуащия, или, точнее, нормативная «схема» исповеди и покаяния. Поэтому такие стихотворения, по существу, мало чем отличаются от текстовдеклараций вроде Transcende te ipsum, утверждающих общезначимый порядок исповедального действия. Исключением из этого ряда можно считать разве что некоторые стихи Римского дневника 1944 года, например, Я посох мой доверил Богу...

\section{Литература}

Davidson P., Hellenism, Culture and Christianity: The Case of Vyacheslav Ivanov and His „Palinode” of 1927, [in:] Russian Literature and The Classics, edited by Peter I. Barta, Amsterdam 1996, p. 83-116.

Jackson R.L., Vjaceslav I. Ivanov and the Question of Art. The Roman Notebook: February 18, 1944 „Nudus Salta! Cel Iskusstva...”, „Russian Literature" 1998, № XLIV.

Kalb J., Lodestars on the Via Appia: Vjaceslav Ivanov `s „Roman Sonnets” in Context, „Die Welt der Slaven” 2003, vol. XLVIII.

Аверинцев С., Стратегия цитаты в поэзии Вячеслава Иванова, „Еuropa Orientalis" 2002, № 1.

Баткин Л., «Не мечтайте о себе»: о культурно-историческом смысле «Я» в «Исповеди» бл. Августина, [в:] Л. Баткин, Европейский человек наедине с собой. Очерки о культурно-исторических основаниях и пределах личного самосознания, Москва 2000.

Блаженный Августин Аврелий, Исповедь, пер. М. Сергиенко, Москва 2005. Блаженный Августин, Творения в 4 томах, т. I, Об истинной религии, Санкт-Петербург - Киев 2000. 
Дудек А., Идеи блаженного Августина в поэтическом восприятии Вяч. Иванова, „Europa Orientalis. Studi e Ricerche sui Paesi e la Culture dell'Est Europeo" 2002, № 1 (XXI), p. 353-367.

Иванов В., Собрание сочинений в 4 томах, Брюссель 1971-1987.

Иванова Л., Воспоминания. Книга об отце, подгот. текста и коммент. Дж. Мальмстада, Москва 1992.

Казанский Н., Исповедъ как литературный жанр, „Вестник истории, литературы и искусства” 2009, т. 6.

Мицкевич Д., Реалиоризм Вячеслава Иванова, [в:] Христианство u русская литература: взаимодействие этнокультурных u религиозно-этических традиций в русской мысли $и$ литературе, Санкт-Петербург 2010.

Цимборска-Лебода М., О понятии «трансцензуса» у Вячеслава Иванова: к проблеме «Вяч. Иванов и Блаженный Августин», [в:] Sub Rosa: Köszöntő köniv Léna Szilárd tiszteletére, Budapest 2005, S. $123-133$.

Шишкин А., Вячеслав Иванович Иванов (1866-1949), [в:] Литература русского зарубежвя (1920-1940): учебник для высших учебных заведений Российской Федерации, отв. ред. Б. Аверин, С. Титаренко, Санкт-Петербург 2011.

\section{References}

Davidson P., Hellenism, Culture and Christianity: The Case of Vyacheslav Ivanov and His „Palinode” of 1927, [in:] Russian Literature and The Classics, edited by Peter I. Barta, Amsterdam 1996, p. 83-116.

Jackson R.L., Vjaceslav I. Ivanov and the Question of Art. The Roman Notebook: February 18, 1944 „Nudus Salta! Cel I Iskusstva...”, „Russian Literature" 1998, № XLIV.

Kalb J., Lodestars on the Via Appia: Vjaceslav Ivanov `s „Roman Sonnets” in Context, „Die Welt der Slaven” 2003, vol. XLVIII.

Averincev S., Strategiya citaty $v$ poe zii Vyacheslava Ivanova, „Europa Orientalis" 2002, № 1.

Batkin L., «Ne mechtajte o sebe»: o kul ‘urno-istoricheskom smy `sle «Ya» $v$ «Ispovedi» bl. Avgustina, [v:] L. Batkin, Evropejskij cheloveknaedine $s$ soboj. Ocherki o kul turno-istoricheskix osnovaniyax $i$ predelax lichnogo samosoznaniya, Moskva 2000.

Blazhenny `j Avgustin Avrelij, Ispoved ’, per. M. Sergienko, Moskva 2005.

Blazhenny $`$ Avgustin, Tvoreniya $v 4$ tomax, t. I, Ob istinnoj religii, SanktPeterburg - Kiev 2000.

Dudek A., Idei blazhennogo Avgustina v poe ‘icheskom vospriyatii Vyach. Ivanova, „Europa Orientalis. Studi e Ricerche sui Paesi e la Culture dell'Est Europeo" 2002, № 1 (XXI), p. 353-367.

Ivanov V., Sobranie sochinenij v 4 tomax, Bryussel `1971-1987. 
Ivanova L., Vospominaniya. Kniga ob otce, podgot. teksta i komment. Dzh. Mal `mstada, Moskva 1992.

Kazanskij N., Ispoved 'kak literaturny `j zhanr, „Vestnik istorii, literatury` i iskusstva" 2009, t. 6.

Miczkevich D., Realiorizm Vyacheslava Ivanova, [v:] Xristianstvo i russkaya literatura: vzaimodejstvie e 'tnokul 'turny ‘ $x$ i religiozno-e ‘ticheskix tradicij v russkoj my `sli i literature, Sankt-Peterburg 2010.

Cimborska-Leboda M., O ponyatii «transcenzusa» $u$ Vyacheslava Ivanova: k probleme «Vyach. Ivanov i Blazhenny j Avgustin», [v:] Sub Rosa: Köszöntö köniv Léna Szilárd tiszteletére, Budapest 2005, s. 123-133.

Shishkin A., Vyacheslav Ivanovich Ivanov (1866-1949), [v:] Literatura russkogo zarubezh ya (1920-1940): uchebnik dlya vy 'sshix uchebny ' $x$ zavedenij Rossijskoj Federacii, otv. red. B. Averin, S. Titarenko, Sankt-Peterburg 2011. 